\section{Training Preservice Mental Health Counselors for Suicide Assessment: A Multiple Baseline Study}

\author{
Teal Bohrer ${ }^{1}$ and Cass Dykeman \\ Oregon State University
}

A Preprint

\begin{abstract}
Rates of death by suicide continue to increase across the United States. Mental health clinicians often have contact with individuals expressing suicidal ideation, but research suggests clinicians may not be appropriately prepared to assess a client's suicide risk. Numerous models and theories explain and assess suicidal ideation. In 2009, Thomas Joiner and his colleagues proposed the interpersonal-psychological theory of suicide (IPT), which focused on three main factors strongly supported by research over the preceding decade. The present study utilized a nonconcurrent, multiple-baseline, multiple-probe design as well as a one-group pretest-posttest design to examine the impact of an IPT-based training model. Participants were preservice mental health clinicians currently enrolled in Master's degree programs. Participants completed assessments on IPT knowledge and suicide-assessment self-efficacy, and results from this study indicated a significant increase in knowledge after completion of the training, as well as a slight decrease in self-efficacy. This study suggests that suicide-assessment training, even when done remotely, can increase suicide-assessment knowledge. Future research should explore preservice mental health clinicians' self-efficacy as well as those factors influencing the confidence these professionals feel in their assessments of risk.
\end{abstract}

Keywords: suicide assessment, interpersonalpsychological theory of suicide, IPT, Thomas Joiner, self-efficacy.

\section{Introduction}

Suicide rates continue to go up in almost every state. From 1999 to 2016, according to the Centers for Disease Control and Prevention (CDC), overall suicide rates for both women and men showed a gradual but steady increase across the United States (2018). In the United States alone, there are approximately 115,580 mental health counselors and 607,300 social workers (Bureau of Labor Statistics, 2016a, 2016b). Unfortunately, research has shown that clinicians on the forefront of this issue often lack the suicide education necessary to treat such an increasingly high-risk population (Jiménez-Chafey, Serra-Taylor, \& Irizarry-Robles, 2013). In the next five years, approximately one million veterans will leave military service and return to civilian life (U.S. Government Accountability Office, 2019), and studies have shown that military veterans are at an increased risk for suicide. Therefore, the need for a sound foundation in suicide knowledge, as well as a sense of self-efficacy when conducting risk assessments, is greater than ever (Bryan, Clemans, \& Hernandez, 2012; Bryan \& Cukrowicz, 2011; Hyman, Ireland, Frost, \& Cottrell, 2012).

Accurately and confidently assessing a client's suicide risk should be a graduate program requirement for mental health clinicians; however, current research suggests a gap between clinical practice and suicide-assessment knowledge and selfefficacy (Jiménez-Chafey et al., 2013). Trainings that teach suicide-assessment theories and skills, which tend to be economical and efficient, have helped to close this gap (Cross, Matthieu, Lezine, \& Knox, 2010). Thomas Joiner's interpersonalpsychological theory of suicide (IPT) is a valuable model for assessing risk and considering contributing risk factors (Van Orden, Witte,

1. Correspondence concerning this article should be addressed to Teal Bohrer, Counseling Academic Unit, Oregon State University, bohrert@oregonstate.edu 
Gordon, Bender, \& Joiner, 2008); research, however, has yet to explore the ability of IPT training to increase knowledge and self-efficacy among individuals preparing to become mental health clinicians. Hence, the need to study the impact IPT training could have on suicide risk assessment.

This introduction reviews five relevant areas of the literature: (a) the impact suicide has on today's society, (b) the amount of contact mental health clinicians have with suicidal clients, (c) the lack of suicide-assessment knowledge and selfefficacy among those most often treating suicidal individuals, (d) how trainings can close the suicideeducation gap many clinicians face, and, (e) IPT and its 3-factor model, along with the research supporting it. Following this review of the literature, the research question guiding this study will be presented.

Suicide is preventable. The Centers for Disease Control and Prevention (as cited in Crosby, Ortega, \& Melanson, 2011) defined suicide as "death caused by self-directed injurious behavior with any intent to die as a result of the behavior" (p. 25). Suicide has been the 10th leading cause of death in the United States, accounting for 36,891 deaths, while also ranking as the 13th leading cause of death worldwide (DeLeo, Bertolote, \& Lester, 2002). Around the world, a suicide occurs every 40 seconds, making for a rate of 14.5 individuals per 100,000 (DeLeo et al., 2002). Among young people, approximately $8.1 \%$ of female high school students reported attempting suicide, along with $4.6 \%$ of male students (CDC, 2014). A suicide attempt is defined as "a non-fatal self-directed potentially injurious behavior with any intent to die as a result of the behavior. A suicide attempt may or may not result in injury" (Crosby et al., 2011, p. 21). Suicide impacts individuals who take their own lives, but it also affects those around them; on average, one completed suicide touches at least six survivors, often family or friends (Jacobson, Osteen, Sharpe, \& Pastoor, 2012).
At the forefront of the suicide epidemic are graduate-level mental health clinicians, individuals who often see suicidal clients in outpatient counseling centers. One study counted $92.8 \%$ of social workers having worked with at least one suicidal client, while more than one third were working with a suicidal client at the time of the study, and more than half reported working with a suicidal client in the previous month (Feldman \& Freedenthal, 2006). Another study on social workers, specifically those entering the counseling field, found that $71 \%$ had worked with at least one actively suicidal client at their current field practicum sites in the previous six months (Jacobson et al., 2012). Lastly, and perhaps most unfortunately, $55 \%$ of clinical social workers reported that, at some point in their careers, at least one of their clients completed suicide (Sanders, Jacobson, \& Ting, 2008).

Thankfully, clinicians have contact with suicidal clients, which is the first step in preventing a suicide; however, it appears this contact is not always successful at preventing the loss of life. Rates of contact with mental health services within one month before a completed suicide average approximately $19 \%$. In the year before suicide, rates of contact average $32 \%$, and lifetime rates of contact with mental health services average $53 \%$ (Luoma, Martin, \& Pearson, 2002). When looking at gender differences, the Luoma et al. (2002) study found that $36 \%$ of women had contact with mental health services prior to their suicides, but only $18 \%$ of men had such contact. This highlights the need to utilize any contact clinicians have with suicidal clients, especially men, who appear more hesitant to seek professional help.

If actively suicidal individuals are having contact with mental health clinicians prior to their deaths, why are they still completing suicide? Within a hospital setting, suicide is one of the most frequent sentinel events in recent years. The Joint Commission (TJC, 2019), a nonprofit organization that certifies and accredits more than 20,500 health care organizations in the United States, defined a 
sentinel event as "an unexpected occurrence involving death or serious physical or psychological injury, or the risk thereof" (p. 1). The organization found that insufficient or absent patient assessment was the root cause in over $80.5 \%$ of suicide deaths, followed by communication errors, which registered at 58\% (TJC, 2019).

A survey of social workers found that only $21.2 \%$ indicated they had received any formal training related to suicide in their Master's-level social work programs (Feldman \& Freedenthal, 2006). Two large groups of community health workers $(n=1,336$ and 1,507$)$ were evaluated and the results showed that many professionals were unaware that individuals aged 65 years and older were at an increased risk for suicide. More than two thirds of the health workers did not know that mental health issues significantly increase suicide risk (Smith, Silva, Covington, \& Joiner, 2014). A 2012 article in the journal Suicide and LifeThreatening Behavior reported that "State licensing boards for clinical social workers, and psychologists, whose mission is to protect the public's health and safety from untrained and unqualified providers, do not require exam items on the assessment and management of suicidal clients" (Schmitz et al., 2012, p. 295). The Schmitz et al. (2012) article further discussed the American Association of Suicidology's task force recommendations for improved suicide prevention, and specifically the fifth recommendation, which states: "Individuals without appropriate graduate or professional training and supervised experience should not be entrusted with the assessment and management of suicidal patients" (p. 9). This suggestion is currently only a recommendation and not yet a standard practice.

Severely depressed clients are slipping through the cracks because of training deficits. A study published in Clinical Child Psychology and Psychiatry found that only $8 \%$ of adolescents evaluated received a diagnosis of depressive disorder using a clinical diagnosis, which involved an unstructured clinical interview considering collateral information and mental status but still leaving the final diagnosis to a doctoral-level clinician's discretion. However, adolescents assessed using a semi-structured interview, via the Schedule for Affective Disorders and Schizophrenia for School-Aged Children, Present and Lifetime Version, received a diagnosis of depressive disorder $28 \%$ of the time (a $20 \%$ increase in diagnoses).

Those receiving a diagnosis of depressive disorder had higher instances of comorbidity, suicidal acts, self-harm, and greater overall functional impairment (Fitzpatrick et al., 2012); this study also highlighted the discrepancy between various forms of assessment for depression and suicide risk.

It appears a lack of training extends beyond U.S. borders. A 2013 study found that mental health clinicians in Puerto Rico had inadequate suicide-screening practices, difficulty exploring and appropriately assessing suicidal ideation, and a lack of knowledge of risk factors (Jiménez-Chafey et al., 2013). The same study found that $51 \%$ of participants received neither suicide training nor education in graduate school. Research internationally has shown the increased need for suicide-assessment training, which is significant because countries other than the United States, such as Greenland and Lithuania, rank highest in suicides per 100,000 individuals, registering averages of 83 and 31, respectively (World Health Organization, 2011).

The present study looked at how training might resolve this hazardous situation. Mental health clinicians need a better understanding of appropriate and effective suicide assessment, and short-term trainings could prove to be the connecting force. Studies have shown that training around suicide increases clinician knowledge, skills, and/or assessment self-efficacy (Crepeau-Hobson, 2013; Fry, 2012; Jacobson, et al., 2012; Reis \& Cornell, 2008; Robinson et al., 2013; Taub et al., 2013). School counselors, mental health clinicians, medical professionals, nonclinical community members, and even university resident assistants have all shown increased understanding and 
knowledge of suicide after receiving training outside their professional or academic educations (CrepeauHobson, 2013; Cross, Matthieu, Cerel, \& Knox, 2007; Cross et al., 2010; da Silva Cais, da Siliveira, Stefanello, \& Botega, 2011; Fry, 2012; Jacobson et al., 2012; Matthieu \& Hensley, 2013; McNiel et al., 2008; Neimeyer, 2001; Pisani, Cross, \& Gould, 2011; Reis \& Cornell, 2008; Robinson et al., 2013; Schmitz et al., 2012; Slaven \& Kisely, 2002; Sockalingam, Flett, \& Bergmans, 2010; Taub et al., 2013; Tompkins \& Witt, 2009).

An article in the journal Suicide and LifeThreatening Behavior found that even high school students felt more confident in their ability to identify high-risk friends and to refer those friends to resources upon receiving education and training (King, Vidourek, \& Strader, 2008). This research is extremely promising, as preventative trainings tend to be short-term and cost-effective. The American Association of Suicidology offers a two-day training costing approximately $\$ 4,500$ to present to a group of 50 people (American Association of Suicidology, 2014). In contrast, society spends approximately $\$ 34.6$ billion annually on the combined medical and loss-of-work costs of suicide (Centers for Disease Control and Prevention, 2018). Trainings could undoubtedly save U.S. individuals and institutions significant money over the long term.

Most current suicide risk assessments rely heavily on risk factors versus protective factors (CDC, 1999; VA, 2013). The CDC identifies 15 risk factors and six protective factors (CDC, 1999), while the VA lists 49 risk factors, with an additional nine for those in the military, as well as 17 protective factors (VA, 2013). Individuals assessed for suicide are often under psychological distress, and thus their ability to accurately disclose 50 or more risk/protective factors could be compromised. The clinician assessing for risk will also face obstacles, as a healthy adult can only store approximately four items at a time in shortterm working memory (Unsworth \& Robison, 2015; Taylor, Thomson, Sutton, \& Donkin 2017). A further complication with this type of assessment criteria is that many risk and protective factors also apply to non-suicidal individuals; thus, generalizing from this method could result in high false-positive predictions (Rudd, 2006).

Thomas Joiner's interpersonal-psychological theory of suicide (IPT) is at the heart of the present study (Joiner, Van Orden, Witte, \& Rudd, 2009). This theory was selected due to its parsimony regarding suicide assessment, parsimony achieved by consolidating the risk and protective factors from preexisting models into one approach with three prongs. For individuals to be considered at risk for suicide under Joiner's IPT, they must (a) have relatively high levels of perceived burdensomeness, (b) feel a sense of failed belongingness, and (c) have the acquired capability to end their own lives. Expanding on emotional dysregulation and IPT, an article by Joiner et al. from 2009 explained: "Early empirical work examining these variables has supported their utility in predicting suicidal desire, with multiple studies demonstrating that the two-way interaction of perceived burdensomeness and thwarted belongingness predicts a distinct but highly related construct: suicidal ideation" (p. 603).

Perceived burdensomeness is indicated when an individual believes they make no meaningful contributions to the world, while instead acting as a liability to others. Individuals with this type of cognitive distortion believe they are defective or flawed, and they see themselves as more valuable in death than they are in life (Joiner et al., 2009). Perceived burdensomeness exists across populations. Research has shown that individuals with a military background, anger issues, an American Indian tribal affiliation, an age over 50 years, clinical obesity, identification as a sexual minority, and chronic pain could feel like a burden to those around them (Bryan et al., 2012; Cukrowicz, Jahn, Graham, Poindexter, \& Williams, 2013; Dutton, Bodell, Smith, \& Joiner, 2013; Hawkins et al., 2014; Hill \& Pettit, 2012; Jahn, Van Orden, \& Cukrowicz, 2013; Kanzler, Craig, McGeary, \& Morrow, 2012; McWilliams, Wilson, 
Kowal, Henderson, \& Peloquin, 2013; O’Keefe et al., 2014).

Contrary to popular belief, research has found a stronger correlation between perceived burdensomeness and suicidal ideation than between hopelessness and suicidal ideation. This correlation was found in participants who had attempted suicide and even more so in those who were actively suicidal (Van Orden, Lynam, Hollar, \& Joiner, 2006). A 2012 study looked at perceived burdensomeness in deployed military service members both with and without traumatic brain injuries. Both groups showed a significant relationship between suicidal ideation and perceived burdensomeness beyond the effects of other risk factors for suicide (Bryan et al., 2012). Perceived burdensomeness has also been significantly correlated with suicidal ideation in university students - a population rarely viewed as a burden to society (Van Orden et al., 2008). Surprisingly, in chronic pain patients, suicidality had a stronger correlation with perceived burdensomeness than it did with endorsed depressive symptoms, pain severity, age, or gender (Kanzler et al., 2012).

Thwarted (or failed) belongingness is the second factor leading to increased suicidal desire. Thwarted belongingness is closely related to loneliness and social isolation. Individuals with a sense of failed belongingness may feel alienated from family, friends, society, or any other valued group (Joiner et al., 2009). Teens who have experienced parental displacement (such as those who were abandoned or who grew up in foster care) after age 15 have higher rates of attempted suicide than do those who have been in consistent contact with their parents. Teens with more suicide attempts also rate themselves as having low levels of belonging and social support, factors that directly align with IPT's concept of thwarted belongingness (Timmons, Edward, Lewinsohn, \& Joiner, 2011).
Patients in a methadone maintenance program were assessed for thwarted belonging using the Interpersonal Needs Questionnaire (Van Orden, Cukrowicz, Witte, \& Joiner, 2012) and were asked about previous suicide attempts and accidental overdoses. Those who had attempted suicide in the past had considerably higher feelings of thwarted belongingness than did those who had not attempted suicide $(d=.75)$. These individuals also showed higher levels of aggression, depression, and hopelessness (Conner, Britton, Sworts, \& Joiner, 2007). Similar results have been found with incarcerated populations and older adults (Cramer, 2012; Cukrowicz et al., 2013).

As a theory, IPT assumes the will to live is stronger than the will to die. To successfully complete suicide, an individual must have endured a significant amount of pain and provocation, endurance often created through past self-harm behaviors such as previous suicide attempts. An individual must be able to overcome the fear and pain associated with carrying out the acts necessary to complete a lethal act of self-injury (Joiner et al., 2009). Engaging in or witnessing violence (e.g., military combat, police work, or bullying) and repeated exposure to pain (e.g., illness or multiple injuries) increases one's acquired capability (Bryan \& Cukrowicz, 2011; Chopko, Palmieri, \& Facemire, 2014; Hyman et al., 2012; Ilgen et al., 2013; Kanzler et al., 2012; Luntamo et al., 2014; McCarthy et al., 2012; McWilliams et al., 2013; Okifuji \& Benham, 2011; Van Orden et al., 2008; Van Tilburg, Spence, Whitehead, Bangdiwala, \& Goldston, 2011).

Most theories on suicide purport that previous suicide attempts increase future risk, reasoning that appears accurate through the lens of acquired capability (Hawkins et al., 2014; Smith, Cukrowicz, Poindexter, Hobson, \& Cohen, 2010; Van Orden et al., 2008). Increased pain tolerance often comes through repeated acts of self-harm. A Psychiatry Research study found that individuals who engaged in repeated self-harm behaviors reported little to no pain during acts of self-harm. Being essentially 
numb to pain, after repeated acts of harm to self, is consistent with the idea that habituated self-harm acts help individuals develop the capacity to commit more serious injuries. This habituation could eventually lead to a lethal act of self-harm (Glenn, Michael, Franklin, Holey, \& Knock, 2014). Finally, international research also supports IPT. A large Australian study of 6,133 citizens, for example, found significant correlations between suicidal ideation and all three factors. The Australian study tested IPT against multiple age groups across adulthood and by gender (Christensen, Batterham, Soubelet, \& Mackinnon, 2013).

With the evident literature gaps and needs, research on training mental health counselors in IPT is necessary. As such, two research questions guided the present study. The first was: What is the impact of IPT-based suicide-assessment training on preservice mental health clinicians' knowledge of IPT-based suicide assessment? And the second was: What is the impact of IPT-based suicide-assessment training on preservice mental health clinicians' suicide intervention self-efficacy?

\section{Method}

\section{Design}

This study employed a nonconcurrent, multiple-baseline, multiple-probe design as well as a one-group pretest-posttest design (Barlow, Hersen, \& Jackson, 1973; Barlow, Nock, \& Hersen, 2009; Gast, Lloyd, \& Ledford, 2014; Watson \& Workman, 1981). The noted designs involve repeated measurements of an outcome over time using a single subject or groups, followed by identification of effects by comparisons of individual or group outcomes in the presence or absence of treatment, across time (Pustejovsky, Hedges, \& Shadish, 2014). This multiple-baseline, multiple-probe design controlled for threats related to history, testing, maturation, and statistical regression (Barlow et al., 2009; Biglan, Ary, \&
Wagenaar, 2000; Christ, 2007). The independent variable was online training on IPT; the dependent variables were participant knowledge around suicide assessment and participants' self-efficacy in accurately assessing risk. Phase A was the baseline phase, and Phase B was the intervention phase.

\section{Participants}

Adults aged 24 to 29 (seven) and 30 to 35 (three), respectively, were recruited with flyers sent out via email through college professors. Nine participants self-identified as Caucasian. The participants included eight females and two males. To fully engage in the online training platform, students needed access to high speed Internet and a camera on their computer. Inclusion criteria also included speaking English and enrollment in a Master's-level counseling program. Students were at varying levels throughout their counseling program; two had taken fewer than 15 credits, four had taken between 15 and 30 credits, three had taken between 31 and 45 credits, and one had taken between 46 and 60 credits.

\section{Measures}

IPT knowledge scale (IPT-KS). The IPT-KS was designed for the current study; it consists of six true-false questions covering the material presented in the slideshow training. A pilot of the questionnaire was conducted, and the mean score of IPT-naive preservice mental health clinicians was 2 $(S D=1.3)$.

\section{Intervening on suicide self-efficacy scale} (ISSE). The ISSE was designed to assess teacher self-efficacy and experiences when intervening with adolescent suicidality (King, Price, Telljohann, \& Wahl, 1999a). This technique assesses efficacy expectations, and each of its six items is measured on a 7-point Likert scale ranging from 1 (strongly disagree) to 7 (strongly agree), allowing totals between 7 and 42. Slight modifications were made to the wording because populations were professional educators but also preservice clinicians 
(i.e., student changed to individual). The measures possess adequate validity and reliability with counselors (King, Price, Telljohann, \& Wahl, 1999b).

\section{Apparatus}

The trainings were delivered via Zoom, a video- and web-conferencing program. According to the product website, over 200,000 organizations use Zoom, including UCLA, Ticketmaster, Stanford Continuing Studies, Uber, and GoDaddy (Zoom, 2019). Zoom allowed participants to log in through the Internet and to join other participants in various locations to learn as a group in a "virtual" classroom. Participants could see the PowerPoint presentation and could engage verbally and through text via a chat box with the trainer and one another. There was no need for participants to download software; the trainer paid for two months of Zoom, costing $\$ 30.00$. Internet connection speed was determined using Speedtest.net, an Internet speed-testing program, and a speed above 12 was required (Ookla, 2015).

Posttest and pretest assessments were provided to participants through a web-based survey system known as Qualtrics. The Qualtrics website describes the company as "the leading global provider of data collection and analysis products for academic research, giving professors and students alike an all-in-one platform to capture real-time insights and draw solid conclusions" (Qualtrics, 2015). Organizations using Qualtrics include Disney, Harvard, Microsoft, and NBC (Qualtrics, 2015).

\section{Procedures}

Participants were aware of the training topic prior to inclusion. All participants gave informed consent according to university guidelines. To attend the training, participants needed access to a computer and a high-speed Internet connection. Study participants were recruited through an email invitation; a list of potential participants was created through the researchers' contacts with doctoral professors, their students, and colleagues. Three groups were created, two with three participants and one with four. Participants were randomly assigned baseline lengths of three, five, or seven sessions, using a random number generator at random.org. Random assignments were as follows: (a) Group A-five-session baseline, (b) Group Bthree-session baseline, and (c) Group C- sevensession baseline.

Given the multiple-probe aspect of the design, the knowledge assessment for Group A occurred at times one and six. For Group B, the knowledge assessments occurred at times one and eight. And, for Group C, knowledge assessments occurred at times one and ten. Each group completed the knowledge scale once during the baseline period and once after intervention. For the self-efficacy assessment, Group A completed baseline assessment at times one, three, four and five, while completing intervention assessments at times six, seven and eight. Group B completed self-efficacy baseline assessments at times one, two and three, with intervention assessments given at times four, five and six. Finally, Group C completed baselines at times one, five, six and seven, with intervention assessments at times eight, nine and ten.

In the end, Group A completed seven selfefficacy assessments, Group B completed six assessments, and Group C completed seven assessments. Three nonconcurrent study periods were conducted, one for each group. Groups met on Tuesdays and Thursdays to either complete a baseline assessment measure or to attend intervention training followed by an assessment measure. Three training sessions were presented via an online web platform (Zoom, 2019), and assessment measures were completed online (Qualtrics, 2015) through direct links provided to participants via e-mail. The study lasted a total of five weeks.

\section{Treatment}


The study followed protocol on IPT as covered in the preceding literature review section. The trainer had completed doctoral-level testing on the protocol and had supervised clinical hours. Three trainings were presented via an online web platform. The first training consisted of a PowerPoint presentation on IPT, which was created and presented by the first author. This training session lasted approximately one hour. The second training, lasting approximately 30 minutes, consisted of a brief case presentation followed by a discussion on how a client would be assessed for suicide risk using IPT. At the end of this training session, participants were asked to utilize IPT skills with family or friends in a role-play situation. The third and final training, also lasting approximately 30 minutes, encouraged participants to discuss their experiences utilizing newly learned skills.

Trainer. The first author conducted the training. This trainer has a Master's degree in counseling psychology from a CACREP university, is a licensed professional counselor with the Oregon Board of Licensed Professional Counselors, and is a certified alcohol and drug counselor level III in Oregon. In terms of professional experience, the trainer spent two years working as a mental health consultant in a large metropolitan maximumsecurity jail and has done several hundred suicide assessments. The trainer currently works as a mobile crisis clinician with a local sheriff's office. The trainer had been supervised by doctoral-level supervisors while using IPT in a clinical setting.

Treatment Fidelity. The trainer utilized fidelity checklists at the end of every training session, and these checklists are available from the first author. The two fidelity raters were doctoral students from a counselor education program. Both raters were trained on IPT and both were supervised throughout the process.

\section{Data Analysis}

For the first research question, a Wilcoxon signed rank test was used to examine the difference between pretest and posttest results. The statistics reported below include the obtained standardized test statistic, $\hat{z}$, and the corresponding probability value, $p$. The observed effect size metric, Cohen's $d$, will also be reported. For the second research question, data evaluation will include both visual analysis and the statistical analysis approach of Nonoverlap of All Pairs (NAP). Lane and Gast's (2014) protocol will facilitate visual analysis. Visual analysis of graphical data, in contrast to statistical analysis of data, is the most frequently used dataanalysis strategy for single-subject research designs (Gast, 2010). The extent to which data in the baseline phases as opposed to the intervention phases do not overlap is an accepted indicator of the amount of performance change (Parker \& Vannest, 2009). For the NAP test, the statistics reported include the NAP scores for each group and the corresponding confidence intervals. Both research questions relied on a significance level of 0.05. To conduct each statistical hypothesis test, the $\mathrm{R}$ programming language was used, and the data were plotted with Microsoft Excel.

\section{Results}

\section{Knowledge (RQ \#1)}

For a lower-tailed Wilcoxon signed rank test, $\hat{z}=-2.7683$. The corresponding $p$ value (using a normal approximation of the $W$ distribution) equaled $0.0028<0.05=\alpha$. This test suggests significant evidence against the null hypothesis in favor of the alternative; intervention is likely associated with increased test scores. The effect size for the sample was $d=|\hat{z}| / \sqrt{n}=0.8754$, which is "large" according to Cohen's criterion (Cohen, 1998). See Figure 1 for a graphical representation of these results.

\section{Self-Efficacy (RQ \#2)}

Plots of the self-efficacy data revealed a slight decrease in scores after intervention. For all three groups, the mean score in Phase B was lower than it was for Phase A. Meanwhile, the overlap-based 
effect size for Groups A, B, and $\mathrm{C}$ was $\mathrm{NAP}=$ $8.33 \%, \mathrm{NAP}=0 \%$, and $\mathrm{NAP}=0 \%$, respectively. These are all small values indicating a large effect size in the negative direction. In other words, the data reveal that intervention was strongly associated with decreased self-efficacy scores in the student population. For Group A, the 95\% confidence interval for $\mathrm{NAP}=8.33 \%$ was $[0 \%$, $31.4 \%$. The trend of diminishing self-efficacy was statistically significant, because the null value of $50 \%$ was not contained in the confidence interval. While reliable confidence intervals cannot be constructed for Groups B and C, NAP $=0 \%$ was the smallest possible value, because there was no overlap between phases in each of these groups. See Figure 2 for a graphical representation of these results.

\section{Discussion}

In terms of the first research question spelled out above, pertaining to increased IPT knowledge, there are two probable reasons for the obtained results. One reason is that participants were able to absorb, process, and retain knowledge due to the creation of an environment conducive to both learning and exposure to new material. Social cognitive theories of learning suggest that selfregulated learning is determined by personal processes as well as by processes influenced by environmental and behavioral events in reciprocal fashion (Zimmerman, 1989). Participants met remotely online during training sessions but were able to interact and ask clarifying questions as needed; so, while the learning environment may not have been a traditional setting, participants were still able to engage in self-regulated learning in an interactive environment, leading to an increase in overall knowledge.

An alternative explanation is that participants absorbed the new knowledge through modeling. This suggests that the trainer's interaction with the material, while also providing mock assessments, presented participants with a model they could use for skill acquisition. However, the former explanation, involving increased knowledge, seems more appropriate, because modeling throughout the training was not substantial enough to facilitate a significant increase in IPT knowledge. Participants are current students, so they were accustomed to self-regulated learning environments.

Two explanations also exist for obtained results indicating decreased self-efficacy among the student population. The first is that student participants came into the study believing they had more risk assessment knowledge and skills than they did. The literature on knowledge and skill acquisition includes multiple studies exploring the phenomenon of presenting new material to professionals. Students' behavioral performances are assumed to influence their perceptions of selfefficacy, with the reverse also being true (Zimmerman, 1989). If students felt their performance on the initial knowledge scale was not as desirable as they had expected, self-efficacy could have been significantly impacted; however, lower self-evaluations will not necessarily diminish overall self-efficacy and motivation if individuals believe they can succeed but that their present approach is what is actually ineffective (Schunk, 2003). A phenomena referred to as "reality shock" proposes that individuals may have unrealistically positive views about their abilities prior to entering a specific career field (Sindu, Richardson, \& Watt, 2018). Thus, exposure to real challenges once immersed in the career may quickly decrease the self-efficacy of these individuals. In this way, after completing the training, students realized they did not initially have the skills and knowledge needed to asses something as significant as suicidal ideation, leading to an overall diminished sense of self-efficacy.

Another explanation for decreased self-efficacy results is that students concluded, after taking the training, that the skills presented to them were too difficult to acquire. Participants may have left the training feeling defeated, as if they could not yet utilize the knowledge and skills learned in a way 
that successfully assessed someone's suicide risk level. Albert Bandura (2012), a leading researcher in self-efficacy, states: "There is a marked difference between possessing knowledge and skills and being able to use them well under diverse circumstances, many of which contain ambiguous, unpredictable, and stressful elements" (p. 25).

Ultimately, the first explanation seems most logical because IPT is used regularly and accurately by many clinicians across many backgrounds and has greater support in the literature.

\section{Limitations}

Limitations for this study include history, generalizability, and testing. Regarding history, participants may have received education on suicide assessment before and/or after the test. Participants were actively engaged in a counseling education program during the study, so there is a possibility they encountered a conversation, lecture, assignment, or reading on suicide that could have impacted study results. However, to increase knowledge results, such outside education would have needed to be specific to IPT.

In terms of overall generalizability, participants in this study were preservice mental health clinicians, so it is unclear whether these findings would generalize across other populations. For example, clinicians who have been practicing in the field for many years could respond differently to new material - or the format in which it was presented. The sample size was also small, making it difficult to assess whether results might be the same among a larger group of participants. Lastly, participants took assessments more than once, and repeated exposure to assessment tools could have decreased scores due to participant fatigue; or, conversely, repeated exposure could have increased scores due to participant learning.

\section{Implications}

Research. Future research may benefit from having a larger sample size to increase the generalizability of the results. Future research could also compare incoming students with graduating students to see whether self-efficacy results differ according to student placement in a Master's program. Qualitative research should also investigate preservice mental health clinicians' personal reservations about assessing potentially suicidal clients' needs. Clinicians must be prepared to assess suicide risk and should feel confident doing so; thus, future research should seek to understand the specific issues keeping students from feeling efficacious in this domain.

Practice. Clinically, this study shows the need for suicide-assessment training in Master's level mental health programs. Despite an increase in knowledge, students left the training doubting their ability to effectively and accurately assess suicide risk. Counseling programs need to provide students with a solid foundation in suicide-assessment theory as well as tools they can use upon graduation. Students should be provided multiple opportunities to utilize theory and skills before completing their degrees.

\section{Conclusion}

In conclusion, the results of this study show that IPT-based suicide-assessment training increased IPT suicide-assessment knowledge in preservice mental health clinicians. However, the study also showed a slight decrease in suicideassessment self-efficacy in preservice mental health clinicians upon completion of the training. These findings suggest that more disciplined education opportunities in Master's-level counseling programs would benefit students but that feelings of efficacy in this area may depend on exposure to real-life situations.

\section{References}

American Psychiatric Association. (2010). Practice guidelines for the assessment and treatment of patients with suicide behaviors. In American Psychiatric 
Association (Ed.), Practice guidelines for the treatment of psychiatric disorders compendium (2nd ed., pp. 835-1027). Arlington, VA: Author.

Bandura, A. (2012). On the functional properties of perceived self-efficacy revisited. Journal of Management, 38(1), 9-44. https://doi/ $10.1177 / 0149206311410606$

Barlow, D. H., Hersen, M., \& Jackson, M. (1973). Single-case experimental designs: Uses in applied clinical research. Archives of General Psychiatry, 29(3), 319-325. https://doi.org/10.1001/archpsyc.1973.042 00030017003

Barlow, D. H., Nock, M. K., \& Hersen, M. (2009). Single case experimental designs: Strategies for studying behavior change (3rd ed.). Boston, MA: Pearson.

Boylan, M. (2001). The self-efficacy of Irish

Guidance Counsellors for identifying and assessing students at risk for suicide. Corvallis, OR: Oregon State University. Retrieved from: https://ir.library.oregonstate.edu/concern/ graduate_thesis_or_dissertations/cz30pv9 $8 \mathrm{~m}$

Bryan, C. J., Clemans, T. A., \& Hernandez, A. M. (2012). Perceived burdensomeness, fearlessness of death, and suicidality among deployed military personnel. Personality and Individual Differences, 52(3), 374-379. https://doi.org/10.1016/j.paid.2011.10.045

Bryan, C. J., \& Cukrowicz, K. C. (2011). Associations between types of combat violence and the acquired capability for suicide. Suicide and Life-Threatening Behavior, 41(2), 126-136. https://doi.org/10.1111/j.1943278X.2011.00023.x

Bureau of Labor Statistics, U.S. Department of Labor (2016a). Mental health counselors. Retrieved from http://www.bls.gov/oes/current/oes211014 .htm

Bureau of Labor Statistics, U.S. Department of Labor (2016b). Occupational outlook handbook: Social workers. Retrieved from http://www.bls.gov/ooh/community-andsocial-service/social-workers.htm

Centers for Disease Control and Prevention. (2013).

Definitions: Self-directed violence.

Retrieved from

http://www.cdc.gov/violenceprevention/su icide/definitions.html

Centers for Disease Control and Prevention. (2016). Suicide prevention - youth suicide.

Retrieved from

http://www.cdc.gov/violenceprevention/pu b/youth_suicide.html

Centers for Disease Control and Prevention. (2018). Press release: Suicide rates rising across the U.S. Retrieved from

https:/www.cdc.gov/media/releases/2018/ p0607-suicide-prevention.html

Chopko, B. A., Palmieri, P. A., \& Facemire, V. C. (2014). Prevalence and predictors of suicidal ideation among U.S. law enforcement officers. Journal of Police and Criminal Psychology, 29(1), 1-9. https://psycnet.apa.org/doi/10.1007/s1189 6-013-9116-z

Christ, T. J. (2007). Experimental control and threats to internal validity of concurrent and nonconcurrent multiple baseline designs. Psychology in the Schools, 44(5), 451-459. http://doi.org/10.1002/pits.20237

Christensen, H., Batterham, P. J., Soubelet, A., \& Mackinnon, A. J. (2013). A test of the interpersonal theory of suicide in a large community-based cohort. Journal of Affective Disorders, 144(3), 225-234. https://doi.org/10.1016/j.jad.2012.07.002

Conner, K. R., Britton, P. C., Sworts, L. M., \& Joiner, T. E., Jr. (2007). Suicide attempts among individuals with opiate dependence: The critical role of belonging. Addictive Behaviors, 32(7), 1395-1404. https://doi.org/10.1016/j.addbeh.2006.09.0 12

Cramer, R. J. (2012). A trait-interpersonal perspective on suicide risk in criminal offenders. Archives of Suicide Research, 
16(4), 334-347.

https://doi.org/10.1080/13811118.2013.722

057

Crepeau-Hobson, F. (2013). An exploratory study of suicide risk assessment practices in the school setting. Psychology in the Schools, 50(8), 810-822. https://doi.org/10.1002/pits.21705

Crosby, A. E., Ortega, L., \& Melanson, C. (2011). Self-directed violence surveillance: Uniform definitions and recommended data elements (Version 1.0). Retrieved from Centers for Disease Control and Prevention website: https://www.cdc.gov/violenceprevention/p df/Self-Directed-Violence-a.pdf

Cross, W., Matthieu, M. M., Cerel, J., \& Knox, K. L. (2007). Proximate outcomes of gatekeeper training for suicide prevention in the workplace. Suicide and LifeThreatening Behavior, 37(6), 659-670. https://doi.org/10.1521/suli.2007.37.6.659

Cross, W., Matthieu, M. M., Lezine, D., \& Knox, K. L. (2010). Does a brief suicide prevention gatekeeper training program enhance observed skills? Crisis: The Journal of Crisis Intervention and Suicide Prevention, 31(3), 149-159. https://doi.org10.1027/0227-5910/a000014

Cukrowicz, K. C., Jahn, D. R., Graham, R. D., Poindexter, E. K., \& Williams, R. B. (2013). Suicide risk in older adults: Evaluating models of risk and predicting excess zeros in a primary care sample. Journal of Abnormal Psychology, 122(4), 1021-1030. https://doi.org/10.1037/a0034953

da Silva Cais, C. F., da Siliveira, I. U., Stefanello, S., \& Botega, N. J. (2011). Suicide prevention training for professionals in the public health network in a large Brazilian city. Archives of Suicide Research, 15(4), 384-389.

https://doi.org/10.1080/13811118.2011.616 152
DeLeo, D., Bertolote, J., \& Lester, D. (2002). Selfdirected violence. In E. Krug, L. Dahlberg, J. Mercy, A. Zwi, \& R. Lozano (Eds.), World report on violence and health (pp. 185-212). Retrieved from https://www.who.int/violence_injury_pre vention/violence/world_report/chapters/e n/

Dutton, G. R., Bodell, L. P., Smith, A. R., \& Joiner, T. E., Jr. (2013). Examination of the relationship between obesity and suicidal ideation. International Journal of Obesity, 37(9), 1282-1286. https://doi.org/10.1038/ijo.2012.224

Feldman, B., \& Freedenthal, S. (2006). Social work education in suicide intervention and prevention: An unmet need? Suicide and Life-Threatening Behavior, 36(4), 467-480. https://doi.org/10.1521/suli.2006.36.4.467

Fitzpatrick, C., Abayomi, N.-N., Kehoe, A., Devlin, N., Glackin, S., Power, L., \& Guerin, S. (2012). Do we miss depressive disorders and suicidal behaviours in clinical practice? Clinical Child Psychology and Psychiatry, 17(3), 449-458. https://doi.org/10.1177/1359104511421101

Fry, J. (2012). Suicide awareness and prevention training in a high security setting. Mental Health Practice, 15(6), 25-31.

https://doi.org/10.7748/mhp2012.03.15.6.2 5.c8980

Gast, D. L. (2010). Single subject research methodology in behavioral sciences. New York, NY: Routledge.

Gast, D. L., Lloyd, B. P., \& Ledford, J. R. (2014). Multiple baseline and multiple probe designs. In D. L. Gast, \& J. R. Ledford (Eds.), Single case research methodology: Applications in special education and behavioral sciences (2nd ed., pp. 251-296). New York, NY: Routledge.

Glenn, J. J., Michel, B. D., Franklin, J. C., Hooley, J. M., \& Nock, M. K. (2014). Pain analgesia among adolescent self-injurers. Psychiatry Research, 220(3), 921-926. 
https://doi.org/10.1016/j.psychres.2014.08. 016

Hawkins, K. A., Hames, J. L., Ribeiro, J. D., Silva, C., Joiner, T. E., Jr., \& Cougle, J. R. (2014). An examination of the relationship between anger and suicide risk through the lens of the interpersonal theory of suicide. Journal of Psychiatric Research, 50, 59-65. https://doi.org/10.1016/j.jpsychires.2013.1 2.005

Hill, R. M., \& Pettit, J. W. (2012). Suicidal ideation and sexual orientation in college students: The roles of perceived burdensomeness, thwarted belongingness, and perceived rejection due to sexual orientation. Suicide and Life-Threatening Behavior, 42(5), 567-579. https://doi.org/10.1111/j.1943278X.2012.00113.x

Hyman, J., Ireland, R., Frost, L., \& Cottrell, L. (2012). Suicide incidence and risk factors in an active duty US military population. American Journal of Public Health, 102(S1), S138-S146. https://doi.org/10.2105/AJPH.2011.300484

Ilgen, M., Kleinberg, F., Ignacio, R., Bohnert, A., Valenstein, M., McCarthy, J., Katz, I. (2013). Noncancer pain conditions and risk of suicide. JAMA Psychiatry, 70(7), 692697. doi:10.1001/jamapsychiatry.2013.908

Jacobson, J., Osteen, P., Sharpe, T., \& Pastoor, J. (2012). Randomized trial of suicide gatekeeper training for social work students. Research on Social Work Practice, 22(3), 270-281. https://doi.org/10.1177/1049731511436015

Jahn, D. R., Van Orden, K. A., \& Cukrowicz, K. C. (2013). Perceived burdensomeness in older adults and perceptions of burden on spouses and children. Clinical Gerontologist, 36(5), 451-459. https://doi.org/10.1080/07317115.2013.816 817

Jiménez-Chafey, M. I., Serra-Taylor, J., \& IrizarryRobles, C. Y. (2013). University mental health professionals in Puerto Rico: Suicide experiences, attitudes, practices, and intervention skills. Journal of College Student Psychotherapy, 27(3), 238-253. https://doi.org/10.1080/87568225.2013.798 225

Joiner, T. E., Jr., Van Orden, K. A., Witte, T. K., \& Rudd, M. D. (2009). The interpersonal theory of suicide: Guidance for working with suicidal clients. Washington, DC: American Psychological Association.

Kanzler, K. E. B., Craig, J., McGeary, D. D., \& Morrow, C. E. (2012). Suicidal ideation and perceived burdensomeness in patients with chronic pain. Pain Practice, 12(8), 602-609. https://doi.org/10.1111/j.15332500.2012.00542.x

King, K. A., Price, J. H., Telljohann, S. K., \& Wahl, J. (1999a). High school health teachers' perceived self-efficacy in identifying students at risk for suicide. Journal of School Health, 69(5), 202-207. https://doi.org/10.1111/j.17461561.1999.tb06386.x

King, K. A., Price, J. H., Telljohann, S. K., \& Wahl, J. (1999b). How confident do school counselors feel in recognizing students at risk for suicide? American Journal of Health Behavior, 23(6), 457-467. https://doi.org/10.5993/AJHB.23.6.5

King, K., Vidourek, R., \& Strader, J. (2008). University students' perceived self-efficacy in identifying suicidal warning signs and helping suicidal friends find campus intervention resources. Suicide and LifeThreatening Behavior, 38(5), 608-617. Retrieved from https://onlinelibrary.wiley.com/doi/abs/10 $.1521 /$ suli.2008.38.5.608

Lane, J. D., \& Gast, D. L. (2014). Visual analysis in single case experimental design studies: Brief review and guidelines. Neuropsychological Rehabilitation, 24(3-4), 445-463. https://doi.org/10.1080/09602011.2013.815 636 
Luntamo, T., Sourander, A., Gyllenberg, D., Sillanmäki, L., Aromaa, M., Tamminen, T., \& Piha, J. (2014). Do headache and abdominal pain in childhood predict suicides and severe suicide attempts? Finnish nationwide 1981 birth cohort study. Child Psychiatry \& Human Development, 45(1), 110-118. https://doi.org/10.1007/s10578-013-0382-x

Luoma, J. B., Martin, C. E., \& Pearson, J. L. (2002). Contact with mental health and primary care providers before suicide: A review of the evidence. American Journal of Psychiatry, 159(6), 909-916. https://doi.org/10.1176/appi.ajp.159.6.909

Matthieu, M., \& Hensley, M. (2013). Gatekeeper training outcomes: Enhancing the capacity of staff in substance abuse treatment programs to prevent suicide in a high risk population. Mental Health and Substance Use, 6(4), 274-286.

https://doi.org/10.1080/17523281.2012.744 342

McCarthy, J. F., Blow, F. C., Ignacio, R. V., Ilgen, M. A., Austin, K. L., \& Valenstein, M. (2012). Suicide among patients in the Veterans Affairs health system: Ruralurban differences in rates, risks, and methods. American Journal of Public Health, 102(S1), S111-S117. https://doi.org/10.2105/AJPH.2011.300463

McNiel, D., Fordwood, S., Weaver, C., Chamberlain, J., Hall, S., \& Binder, R. (2008). Effects of training on suicide risk assessment. Psychiatric Services, 59(12), 1462-1465. https://doi.org/10.1176/appi.ps.59.12.1462

McWilliams, L., Wilson, K., Kowal, J., Henderson, P. R., \& Peloquin, K. (2013). Chronic pain and the interpersonal theory of suicide. Rehabilitation Psychology, 58(1), 111-115. https://doi.org/10.1037/a0031390

Neimeyer, R. A. (2001). Personal and professional factors and suicide intervention skills. Suicide and Life-Threatening Behavior,
31(1), 71-82.

https://doi.org/10.1521/suli.31.1.71.21307

O’Keefe, V. M., Wingate, L. R., Tucker, R. P., Rhoades-Kerswill, S., Slish, M. L., \& Davidson, C. L. (2014). Interpersonal suicide risk for American Indians: Investigating thwarted belongingness and perceived burdensomeness. Cultural Diversity and Ethnic Minority Psychology, 20(1), 61-67.

https://doi.org/10.1037/a0033540

Okifuji, A., \& Benham, B. (2011). Suicidal and selfharm behaviors in chronic pain patients.

Journal of Applied Biobehavioral Research, 16(2), 57-77.

https://doi.org/10.1111/j.1751-

9861.2011.00065.x

Ookla, LLC (2015). Speedtest.net - The Global

Broadband Speed Test. Seattle, WA:

Author. Retrieved

from https://www.speedtest.net/

Parker, R. I., \& Vannest, K. (2009). An improved effect size for single-case research: Nonoverlap of all pairs. Association for Behavioral and Cognitive Therapies, 40, $357-367$. https://doi.org/10.1016/j.beth.2008.10.006

Pisani, A. R., Cross, W. F., \& Gould, M. S. (2011). The assessment and management of suicide risk: State of workshop education. Suicide and Life-Threatening Behavior, 41(3), 255276. https://dx.doi.org/10.1111\%2Fj.1943278X.2011.00026.X

Pustejovsky, J. E., Hedges, L. V., \& Shadish, W. R. (2014). Design-comparable effect sizes in multiple baseline designs: A general modeling framework. Journal of Educational and Behavioral Statistics, 39(5), 368-393. https://doi.org/10.3102/1076998614547577

Qualtrics (Version 2015) [Computer software]. Provo, UT: Qualtrics Lab, Inc.

Reis, C., \& Cornell, D. (2008). An evaluation of suicide gatekeeper training for school counselors and teachers. Professional School Counseling, 11(6), 386-394. 
https://doi.org/10.1177\%2F2156759X08011 00605

Robinson, J., Cox, G., Malone, A., Williamson, M., Baldwin, G., Fletcher, K., \& O'Brien, M. (2013). A systematic review of schoolbased interventions aimed at preventing, treating, and responding to suicide-related behavior in young people. Crisis: The Journal of Crisis Intervention and Suicide Prevention, 34(3), 164-182.

https://doi.org/10.1027/0227$5910 / \mathrm{a} 000168$

Sanders, S., Jacobson, J., \& Ting, L. (2008).

Preparing for the inevitable: Training social workers to cope with client suicide. Journal of Teaching in Social Work, 28(12), 1-18. https://doi.org/10.1080/0884123080217882 1

Schmitz, W. M., Allen, M. H., Feldman, B. N., Gutin, N. J., Jahn, D. R., Kleespies, P. M. \& Simpson, S. (2012). Preventing suicide through improved training in suicide risk assessment and care: An American Association of Suicidology task force report addressing serious gaps in U.S. mental health training. Suicide and Life-

Threatening Behavior, 42(3), 292-304. https://doi.org/10.1111/j.1943278X.2012.00090.x

Schunk, D. H. (2003). Self-efficacy for reading and writing: Influence of modeling, goal setting, and self-evaluation. Reading \& Writing Quarterly, 19(2), 159-172. Retrieved from https://libres.uncg.edu/ir/uncg/f/D_Schu nk_Self_2003.pdf

Sindu, G., Richardson, P., Watt, H., (2018). Early career teachers' self-efficacy: A longitudinal study from Australia. Australian Journal of Education, 62(2), 217-233. https://doi.org/10.1177/0004944118779601

Slaven, J., \& Kisely, S. (2002). The Esperance primary prevention of suicide project. Australian and New Zealand Journal of Psychiatry, 36(5), 617-621. https://doi.org/10.1046/j.14401614.2002.01074.x

Smith, A. R., Silva, C., Covington, D. W., \& Joiner, T. E., Jr. (2014). An assessment of suicide-related knowledge and skills among health professionals. Health Psychology, 33(2), 110-119. https://doi.org/10.1037/a0031062

Smith, P. N., Cukrowicz, K. C., Poindexter, E. K., Hobson, V., \& Cohen, L. M. (2010). The acquired capability for suicide: A comparison of suicide attempters, suicide ideators, and non-suicidal controls. Depression and Anxiety, 279), 871-877. http://doi.org/10.1002/da.20701

Sockalingam, S., Flett, H., \& Bergmans, M. Y. (2010). A pilot study in suicide intervention training using a group intervention for patients with recurrent suicide attempts. Academic Psychiatry, 34(2), 132-135. https://doi.org/10.1176/appi.ap.34.2.132

Taub, D. J., Servaty-Seib, H. L., Miles, N., Lee, JY., Morris, C. A. W., Prieto-Welch, S. L., \& Werden, D. (2013). The impact of gatekeeper training for suicide prevention on university resident assistants. Journal of College Counseling, 16(1), 64-78. https://doi.org/10.1002/j.21611882.2013.00027.x

The Joint Commission. (2019). Sentinel event.

Retrieved from

http://www.jointcommission.org/sentinel_ event.aspx

Timmons, K. A., Selby, E. A., Lewinsohn, P. M., \& Joiner, T. E., Jr. (2011). Parental displacement and adolescent suicidality: Exploring the role of failed belonging. Journal of Clinical Child \& Adolescent Psychology, 40(6), 807-817. https://doi.org/10.1080/15374416.2011.614 584

Tompkins, T. L., \& Witt, J. (2009). The short-term effectiveness of a suicide prevention gatekeeper training program in a college setting with residence life advisers. The 
Journal of Primary Prevention, 30(2), 131149. https://doi.org/10.1007/s10935-009-

0171-2

U.S. Government Accountability Office. (2019).

Transitioning veterans: Improved oversight needed to enhance implementation of transition assistance program. Retrieved from http://www.gao.gov/assets/670/661362.pd f

Vannest, K. J., Parker, R. I., \& Gonen, O. (2011). Single Case Research: Web-based calculators for SCR analysis. (Version 1.0) [Web-based application]. College Station, TX: Texas A\&M University. Retrieved from http://www.singlecaseresearch.org

Van Orden, K. A., Cukrowicz, K. C., Witte, T. K., \& Joiner, T. E., Jr. (2012). Thwarted belongingness and perceived burdensomeness: Construct validity and psychometric properties of the Interpersonal Needs Questionnaire. Psychological Assessment, 24(1), 197-215. https://doi.org/10.1037/a0025358

Van Orden, K. A., Lynam, M. E., Hollar, D., \& Joiner, T. E., Jr. (2006). Perceived burdensomeness as an indicator of suicidal symptoms. Cognitive Therapy and Research, 30(4), 457-467. https://doi.org/10.1007/s10608-006-9057-2

Van Orden, K. A., Witte, T. K., Gordon, K. H., Bender, T. W., \& Joiner, T. E., Jr. (2008). Suicidal desire and the capability for suicide: Tests of the interpersonalpsychological theory of suicidal behavior among adults. Journal of Consulting and Clinical Psychology, 76(1), 72-83. https://doi.org/10.1037/0022-006X.76.1.72 Van Tilburg, M. A. L., Spence, N. J., Whitehead, W. E., Bangdiwala, S., \& Goldston, D. B. (2011). Chronic pain in adolescents is associated with suicidal thoughts and behaviors. Journal of Pain, 12(10), 10321039. https://doi.org/10.1016/j.jpain.2011.03.004

Watson, P. J., \& Workman, E. A. (1981). The nonconcurrent multiple baseline acrossindividuals design: An extension of the traditional multiple baseline design.

Journal of Behavior Therapy and Experimental Psychiatry, 12(3), 257-259. https://doi.org/10.1016/00057916(81)90055-0

World Health Organization. (2011). Suicide rates per 100,000 by country, year, and sex.

Retrieved from http://www.who.int/mental_health/preve ntion/suicide_rates/en/

Zimmerman, B. J. (1989). A social cognitive view of self-regulated academic learning. Journal of Educational Psychology, 81(3), 329-339. http://doi.org/10.1037/0022-0663.81.3.329

Zoom Video Communications. (2019). Zoom [software]. San Jose, CA: Author. Retrieved from https://zoom.us/ 


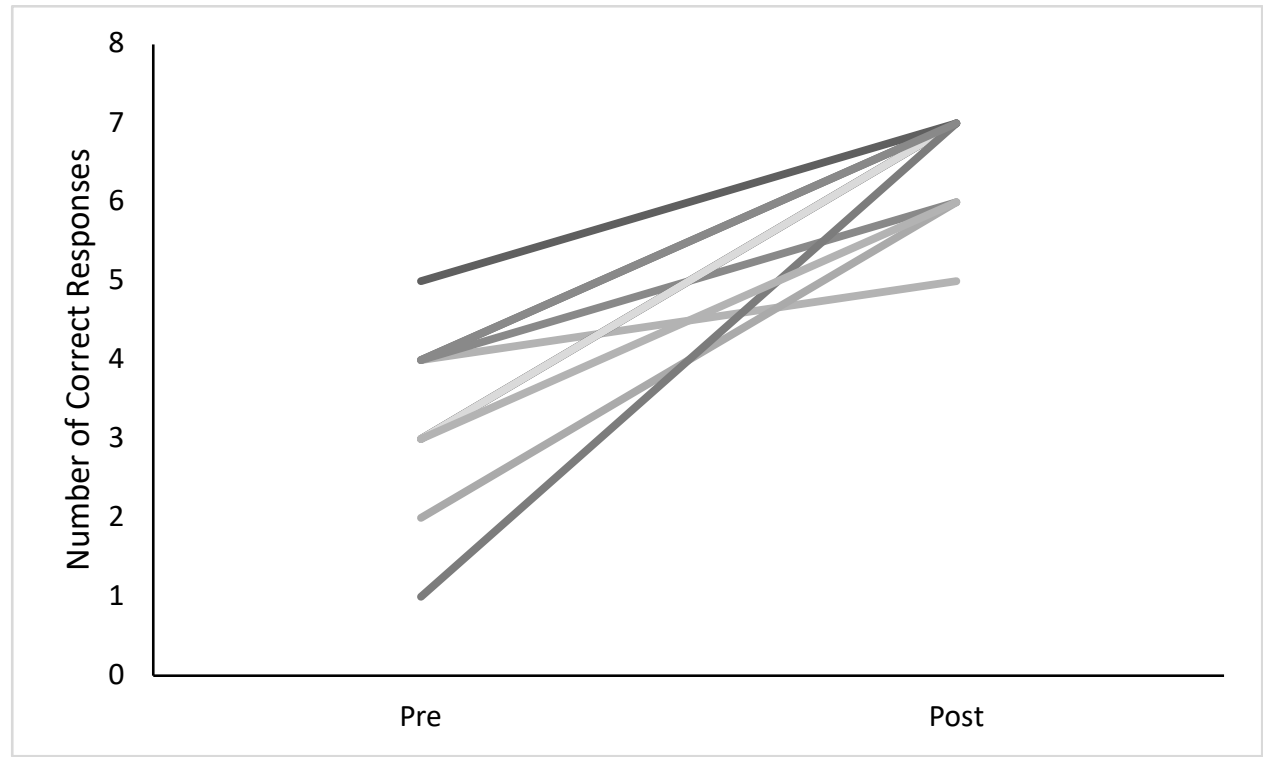

Figure 1. Individual Pretest and Posttest Scores for Knowledge 


\section{Group B}
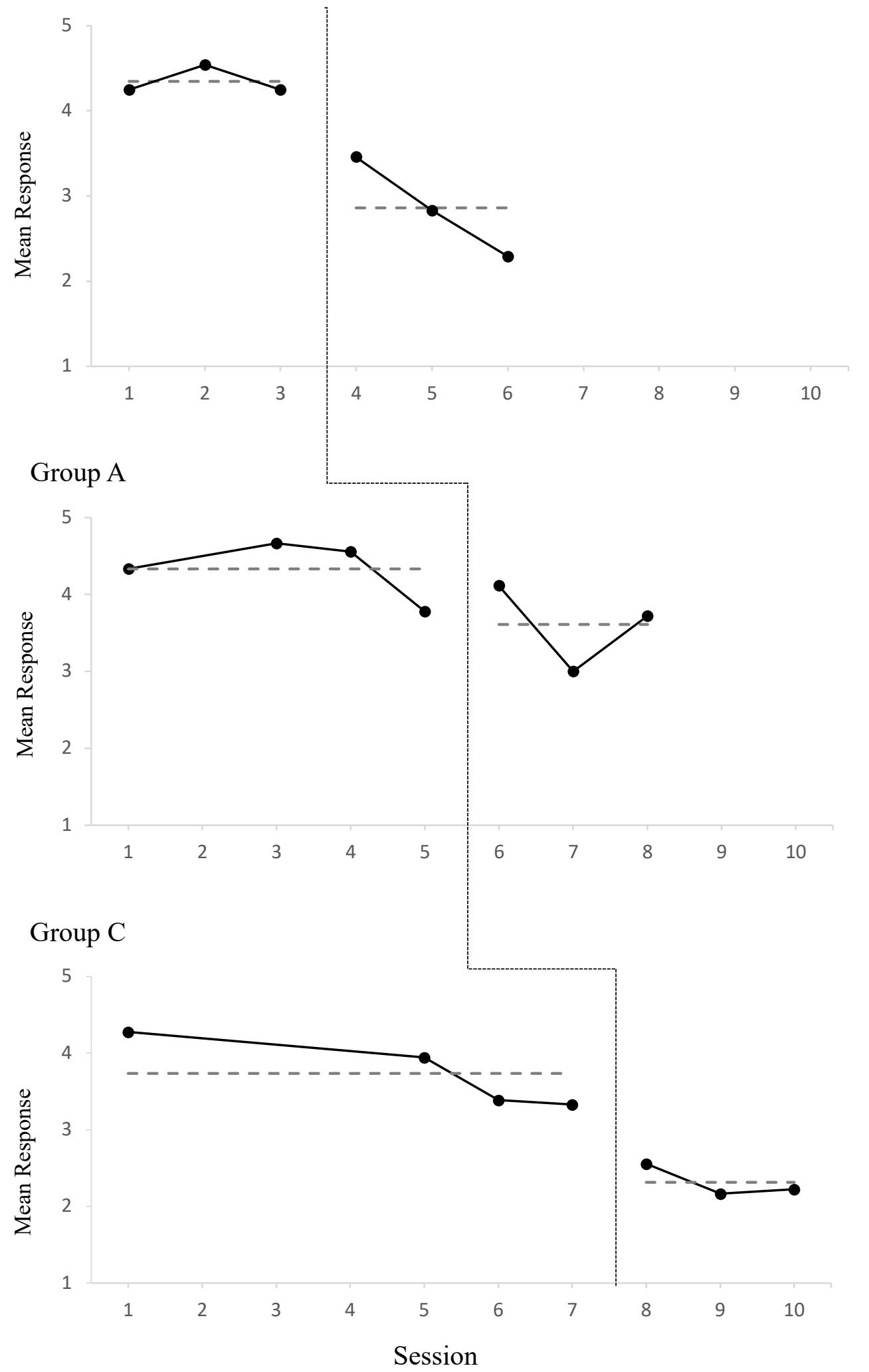

Figure 2. Self-Efficacy Test Scores Over Time 